\title{
Investigation of evaporation characteristics of polonium and its lighter homologues selenium and tellurium from liquid Pb-Bi-eutecticum
}

\author{
By J. Neuhausen ${ }^{1, *}$, U. Köster ${ }^{2}$ and B. Eichler ${ }^{1}$ \\ ${ }^{1}$ Laboratory for Radio- and Environmental Chemistry, Paul Scherrer Institute, CH-5232 Villigen PSI, Switzerland \\ ${ }^{2}$ CERN, ISOLDE, CH-1211 Genève 23, Switzerland
}

(Received February 4, 2004; accepted in revised form May 13, 2004)

\section{Chalcogens / Polonium / Release / Pb-Bi-eutecticum / Evaporation / Thermochemistry}

Summary. The evaporation behaviour of polonium and its lighter homologues selenium and tellurium dissolved in liquid $\mathrm{Pb}$-Bi-eutecticum (LBE) has been studied at various temperatures in the range from $482 \mathrm{~K}$ up to $1330 \mathrm{~K}$ under $\mathrm{Ar} / \mathrm{H}_{2}$ and $\mathrm{Ar} / \mathrm{H}_{2} \mathrm{O}$-atmospheres using $\gamma$-ray spectroscopy. Polonium release in the temperature range of interest for technical applications is slow. Within short term $(1 \mathrm{~h})$ experiments measurable amounts of polonium are evaporated only at temperatures above $973 \mathrm{~K}$. Long term experiments reveal that a slow evaporation of polonium occurs at temperatures around $873 \mathrm{~K}$ resulting in a fractional polonium loss of the melt around $1 \%$ per day. Evaporation rates of selenium and tellurium are smaller than those of polonium. The presence of $\mathrm{H}_{2} \mathrm{O}$ does not enhance the evaporation within the error limits of our experiments. The thermodynamics and possible reaction pathways involved in polonium release from LBE are discussed.

\section{Introduction}

Liquid lead-bismuth eutecticum (LBE) is proposed to be used as target material in spallation neutron sources [1] as well as in accelerator driven systems (ADS) for the transmutation of long-lived nuclear waste [2]. In these systems polonium is formed as a product of $(p, x n)$ and $(n, \gamma)$-reactions according to the following processes:

$$
\begin{aligned}
& { }^{209} \mathrm{Bi} \stackrel{(p, x n)}{\longrightarrow}{ }^{208,209} \mathrm{Po}, \\
& { }^{209} \mathrm{Bi} \stackrel{(n, \gamma)}{\longrightarrow}{ }^{210} \mathrm{Bi} \stackrel{\beta^{-}}{\longrightarrow}{ }^{210} \mathrm{Po} .
\end{aligned}
$$

Within 1 year of operation employing a proton beam current of $1 \mathrm{~mA}$ around $2 \mathrm{~g}$ of polonium are produced in this manner [3]. Because of the high radiotoxicity of polonium its behaviour is of utmost importance with respect to the safe operation and post-irradiation handling of the target systems and materials as well as for an assessment of the potential risk of accident scenarios.

\footnotetext{
*Author for correspondence (E-mail: joerg.neuhausen@psi.ch).
}

While the rates of evaporation and transport are of interest for an evaluation of the risk of contamination and incorporation in case of an accident, the development of suitable techniques for the fixation of polonium requires a fundamental knowledge of the chemical mechanisms of the release process.

Previous thermal evaporation studies on polonium from molten $\mathrm{Bi}$ and $\mathrm{Pb}$-Bi-eutecticum dealt with the preparation of polonium by neutron irradiation of bismuth and subsequent separation by distillation $[4,5]$ and hazards related to the technical use of LBE in nuclear devices [6-8]. The thermodynamics of polonium release from molten LBE at temperatures between 673 and $823 \mathrm{~K}$ is investigated in [9]. Additionally, calculations of the polonium release rate based on a Langmuir-type formalism are reported [10-13].

The chemical mechanism of the release of volatiles can be influenced by the composition of the vapour phase. Hydrogen will be formed by spallation reactions in the operating target. Therefore, a certain amount of $\mathrm{H}_{2} \mathrm{O}$ will be present in the system, where the vapour pressure of $\mathrm{H}_{2} \mathrm{O}$ depends on the oxide content of the liquid alloy. In case of an accident, the alloy can be exposed to air.

In this work we study the thermal release of polonium and its lighter homologues selenium and tellurium from LBE in an inert gas/hydrogen atmosphere. Some additional experiments employing an inert gas/water atmosphere were also conducted.

\section{Experimental}

Pieces of eutectic $\mathrm{Pb} / \mathrm{Bi}$-alloy (44.8 wt.\% $\mathrm{Pb}, 55.2$ wt. \% $\mathrm{Bi}$, Impag AG, Switzerland, impurities (ppm): Ag 11.4, Fe 0.78, Ni 0.42, Sn 13.3, Cd 2.89, Al 0.3, Cu 9.8, Zn 0.2, $\mathrm{Se}<2, \mathrm{Te}<2$ ) of dimensions appr. $10 \times 10 \times 1.5 \mathrm{~mm}^{3}$ have been doped with ${ }^{75} \mathrm{Se},{ }^{121} \mathrm{Te}$ and ${ }^{206} \mathrm{Po}$ by implantation of mass-separated radioactive ion beams at the on-line isotope separator ISOLDE at CERN.

${ }^{206} \mathrm{Po}$ was prepared indirectly, by implantation of the precursors ${ }^{206} \mathrm{Rn}\left(T_{1 / 2}=2.7 \mathrm{~min}\right)$ and ${ }^{210} \mathrm{Fr}\left(T_{1 / 2}=3.2 \mathrm{~min}\right)$ respectively. The ${ }^{206} \mathrm{Rn}$ beams were produced by $1.4 \mathrm{GeV}$ proton-induced spallation of a $50 \mathrm{~g} / \mathrm{cm}^{2}{ }^{238} \mathrm{UC}_{x}$ target $(x \approx$ 4) connected via a water-cooled transfer line to a FEBIAD 
ion source [14]. The condensation of non-volatile isobars in the transfer line assures beams of high isotopic purity ( $\gg 99.9 \%$ ). About $38 \%$ [15] of the ${ }^{206} \mathrm{Rn}$ decays via $\left(\beta^{+} / \mathrm{EC}\right) \rightarrow{ }^{206} \mathrm{At} \rightarrow\left(\beta^{+} / \mathrm{EC}\right)$ to ${ }^{206} \mathrm{Po}$, the remaining $62 \%$ populate ${ }^{202 \mathrm{~g}} \mathrm{~Pb}$ and ${ }^{198} \mathrm{~Pb} /{ }^{198} \mathrm{Tl}$, which do not contribute any measurable activity after some days of decay. The beam intensity was about $2 \times 10^{8}{ }^{206} \mathrm{Rn}^{+}$ions per $\mathrm{s}$, allowing to collect $4 \mathrm{kBq}{ }^{206}$ Po per minute.

On another occasion a $50 \mathrm{~g} / \mathrm{cm}^{2}{ }^{238} \mathrm{UC}_{x}$ target connected via a high temperature transfer line to a tungsten surface ionizer was used. All parts were kept above $2000^{\circ} \mathrm{C}$. About $98 \%$ of the ${ }^{210} \mathrm{Fr}$ decays via $\mathrm{EC} / \beta^{+} \rightarrow{ }^{210} \mathrm{Rn} \rightarrow \alpha \rightarrow$ or via $\alpha \rightarrow{ }^{206} \mathrm{At} \rightarrow \mathrm{EC} / \beta^{+} \rightarrow$ to ${ }^{206} \mathrm{Po}$. Again the side branches of the decay chain do not contribute any measurable activity after some days of decay. The beam intensity of ${ }^{210} \mathrm{Fr}$ of about $2 \times 10^{8}$ ions per $\mathrm{s}$ results in a production of $10 \mathrm{kBq}$ ${ }^{206}$ Po per minute.

Also ${ }^{121} \mathrm{Te}$ was produced indirectly by implantation of the precursors ${ }^{121 \mathrm{~g}+\mathrm{m}} \mathrm{Cs}$ which decay by $\beta^{+} / \mathrm{EC}$ via ${ }^{121} \mathrm{Xe}$ and ${ }^{121} \mathrm{I}$ to ${ }^{121} \mathrm{Te}$. ${ }^{121} \mathrm{Cs}$ was produced from the same $\mathrm{UC}_{x}$ target as above by $1.4 \mathrm{GeV}$ proton-induced spallation-fission and then surface ionised. Despite the unfavourable target and ion source combination (neutron-deficient nuclides are much better produced by spallation of a close-by target nucleus), a ${ }^{121} \mathrm{Cs}$ beam intensity better than $3 \times 10^{7}$ ions per $\mathrm{s}$ allowed to collect about $1 \mathrm{kBq}{ }^{121}$ Te per minute.

${ }^{75} \mathrm{Se}$ was produced by $1.4 \mathrm{GeV}$ proton-induced spallation of a $11 \mathrm{~g} / \mathrm{cm}^{2}$ zirconia fibre target connected via an unselective, hot transfer line to a FEBIAD ion source [16]. The cumulative ion beam intensity of ${ }^{75} \mathrm{Se}^{+}$plus precursors $\left({ }^{75} \mathrm{Br},{ }^{75} \mathrm{Kr},{ }^{75} \mathrm{Rb}\right)$ was about $5 \times 10^{8}$ ions per s, allowing to collect $2 \mathrm{kBq}$ of ${ }^{75} \mathrm{Se}$ within 1 minute.

The samples doped with ${ }^{75} \mathrm{Se},{ }^{121} \mathrm{Te}$ and ${ }^{206} \mathrm{Po}$ were cut in pieces and afterwards melted and heated at $673 \mathrm{~K}$ for 1 hour together with additional LBE reduced under a hydrogen atmosphere to achieve homogeneous distribution of radionuclides as well as suitable sample sizes and activities suitable for measurement by $\gamma$-ray spectroscopy. No additional carrier was added.

For the long-term release studies LBE containing ${ }^{205} \mathrm{Bi}$ produced by neutron activation was used for diluting the samples in the same manner as described above. ${ }^{205} \mathrm{Bi}$ was used as an internal standard for the evaluation of $\gamma$-ray spectra to correct for changes in sample shape frequently occurring on melting. For short-term experiments ${ }^{206} \mathrm{Bi}$ produced by decay of ${ }^{206}$ Po was used as standard.

The number of nuclei and concentrations of ${ }^{75} \mathrm{Se},{ }^{121} \mathrm{Te}$ and ${ }^{206} \mathrm{Po}$ were determined from the peak areas of characteristic $\gamma$-rays of the respective nuclide $\left({ }^{75} \mathrm{Se}: 400.66 \mathrm{keV}\right.$, ${ }^{121} \mathrm{Te}: 573.14 \mathrm{keV},{ }^{206} \mathrm{Po}: 1032.26 \mathrm{keV}$ ) taking into account the detector efficiency and $\gamma$-branching [17]. Selfabsorption effects were roughly estimated based on sample thickness and mass attenuation coefficients listed in [18]. Estimated experimental errors of number of nuclei and concentrations are $40 \%$ for ${ }^{75} \mathrm{Se}, 25 \%$ for ${ }^{121} \mathrm{Te}$ and $15 \%$ for ${ }^{206} \mathrm{Po}$ resulting mainly from the crude evaluation of selfabsorption effects.

Typical numbers of nuclei were in the range of $4 \times 10^{8}$ to $5 \times 10^{9}$ for ${ }^{121} \mathrm{Te}$ and ${ }^{206} \mathrm{Po}$ containing LBE samples and $2 \times 10^{10}$ to $5 \times 10^{10}$ for ${ }^{75} \mathrm{Se}$ containing LBE samples. Typical sample masses for short-term (1 hour) experiments were
$2.5 \mathrm{~g}\left({ }^{75} \mathrm{Se}\right.$ samples $)$ and $0.13-0.88 \mathrm{~g}\left({ }^{121} \mathrm{Te} /{ }^{206} \mathrm{Po}\right.$ samples $)$, whereas for long term studies on the release of ${ }^{121} \mathrm{Te}$ and ${ }^{206}$ Po larger samples $(2.5-7.5 \mathrm{~g})$ have been used. The resulting mole fractions at the start of the experiment were in the range of $3 \times 10^{-13}$ to $2.5 \times 10^{-12}$ for ${ }^{121} \mathrm{Te} /{ }^{206} \mathrm{Po}$ containing samples and 3.2 to $7.3 \times 10^{-12}$ for ${ }^{75} \mathrm{Se}$ containing samples.

Evaporation experiments (one experiment for each temperature setting) were performed using the experimental setup illustrated in Fig. 1. Before the experiment, the samples were scratched to remove the surface oxide layer. The samples were then placed on a quartz tissue within a quartz boat, which was placed in a quartz tube. This tube was flushed with an $\mathrm{Ar} / 7 \%-\mathrm{H}_{2}$ mixture (purity: $\mathrm{H}_{2}>99.993 \%$, $\mathrm{Ar}>99.998 \%$ ), which was previously run through a column containing a Pd-contact to facilitate the establishment of $\mathrm{O}_{2} / \mathrm{H}_{2} / \mathrm{H}_{2} \mathrm{O}$ equilibrium and Sicapent (with indicator, Merck, Germany) for removing moisture. A partial pressure of water of $3.7 \pm 1.7 \mathrm{hPa}$ was determined using a $\mathrm{Zr} / \mathrm{Y}_{2} \mathrm{O}_{3}$ solid electrolyte cell.

Some additional experiments were performed in a water saturated Ar atmosphere. For this, $\operatorname{Ar}$ (purity > 99.998\%) was bubbled though a washing bottle containing water at room temperature and the drying column was removed.

All experiments were performed using a continuous gas flow of $60 \mathrm{ml} / \mathrm{min}$ adjusted by a mass flow controller. The apparatus was flushed for approximately $20 \mathrm{~min}$ after the insertion of the sample to remove air contamination.

The tube was resistance-heated to the desired temperatures. Temperatures were measured and controlled using thermocouples and a thyristor controller. Two charcoal filters were placed at the end of the tube to prevent volatile radioactive species reaching the exhaust.

$\gamma$-ray spectroscopic measurements were performed using an HPGe-detector.

Short-term experiments: A $\gamma$-ray spectrum of the sample was recorded before each heating experiment. The sample was then placed into the evaporation apparatus, which was flushed with the appropriate gas mixture. After approximately $20 \mathrm{~min}$, the apparatus was heated to the desired temperature within $10 \mathrm{~min}$ and kept at this temperature for $50 \mathrm{~min}$. Subsequently, the sample was cooled to room temperature within 10 min using a fan. A $\gamma$-ray spectrum was recorded after the experiment (typical measuring time: 1 hour). The fractional release of the chalcogens was calculated comparing the integrated peak areas of the following characteristic $\gamma$-rays of the respective nuclides $\left({ }^{75} \mathrm{Se}: 264.66,279.54\right.$, and $400.66 \mathrm{keV} ;{ }^{121} \mathrm{Te}: 507.59$ and $573.14 \mathrm{keV}$; ${ }^{206}$ Po: 286.41, 311.56, 338.44, 522.47, 980.23 and $1032.26 \mathrm{keV} \mathrm{[17])} \mathrm{before} \mathrm{and} \mathrm{after} \mathrm{heating.} \mathrm{The} \mathrm{error}$

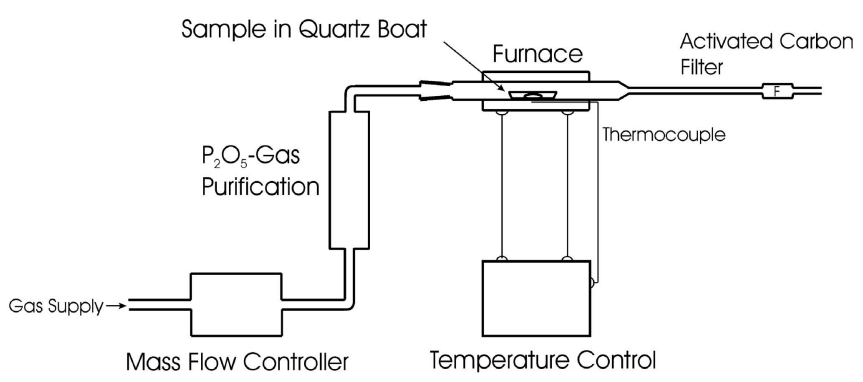

Fig. 1. Schematic drawing of the experimental set-up. 
bars given in the figures correspond to the standard errors of the mean values obtained by averaging the fractional release calculated for each characteristic $\gamma$-ray of the respective nuclide. Given the half-lives of the present nuclides $\left({ }^{75} \mathrm{Se}\right.$ : $119.8 \mathrm{~d} ;{ }^{121} \mathrm{Te}: 16.8 \mathrm{~d}$; ${ }^{206} \mathrm{Po}: 8.8 \mathrm{~d}$ [17]) a decay correction was omitted for these short-term experiments. However, ${ }^{206} \mathrm{Bi}\left(t_{1 / 2}=6.24 \mathrm{~d}[17]\right)$, which is formed by decay of ${ }^{206} \mathrm{Po}$, has been used as an internal standard to correct for geometry and self-absorption changes that may occur between the measurements before and after heating due to the melting process. For this purpose, the peak area ratios before and after heating for characteristic $\gamma$-rays of the internal standard lying energetically close to characteristic $\gamma$-rays of the investigated volatile nuclides were determined and the signals of the volatiles were corrected accordingly. No measurable evaporation of $\mathrm{Bi}$ was detected at temperatures below $1280 \mathrm{~K}$. For the three samples heated at temperatures higher than $1280 \mathrm{~K}$ a small loss of $\mathrm{Bi}$ was observed giving rise to a small underestimation (about 1\%) of the respective release values for the chalcogens.

Long-term experiments: In principle, the same experimental set-up was used as in the short-term experiments. However, the samples were kept in the apparatus for periods from 10 days up to several weeks with intermittent coolingmeasuring-heating-up-cycles as described above. For the evaluation of these measurements a decay correction was applied to the integrated peak areas of the $\gamma$-ray signals of both volatile species and internal standard. ${ }^{206} \mathrm{Bi}$ could not be used as an internal standard because it is permanently produced by decay of ${ }^{206} \mathrm{Po}$. Therefore, ${ }^{205} \mathrm{Bi}$-containing LBE was used to dilute the samples and this isotope was used as standard.

\section{Results and discussion}

The results of the short-term evaporation experiments are shown in Fig. 2-4. A comparison of the release behaviour of selenium, tellurium and polonium from LBE $(1 \mathrm{~h}$ experiments) in an $\mathrm{Ar} / 7 \%-\mathrm{H}_{2}$ atmosphere at temperatures between 482 and $1330 \mathrm{~K}$ is shown in Fig. 2. Measurable amounts of

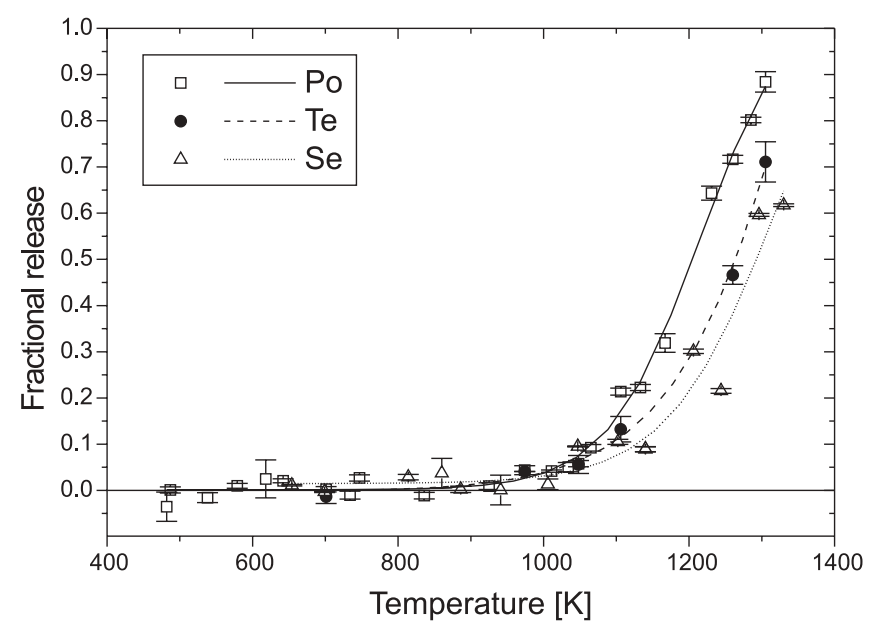

Fig. 2. Comparison of the release behaviour of selenium, tellurium and polonium from LBE ( $1 \mathrm{~h}$ experiments) in an $\mathrm{Ar} / 7 \%-\mathrm{H}_{2}$ atmosphere as a function of temperature.

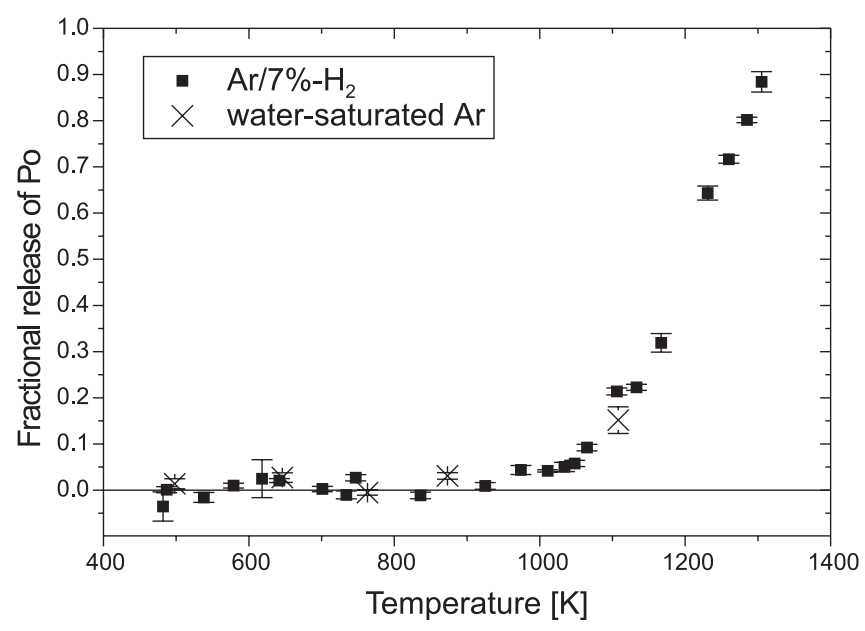

Fig. 3. Comparison of the release of polonium from LBE ( $1 \mathrm{~h}$ experiments) in $\mathrm{Ar} / 7 \%-\mathrm{H}_{2}$ and water saturated Ar atmospheres as a function of temperature.

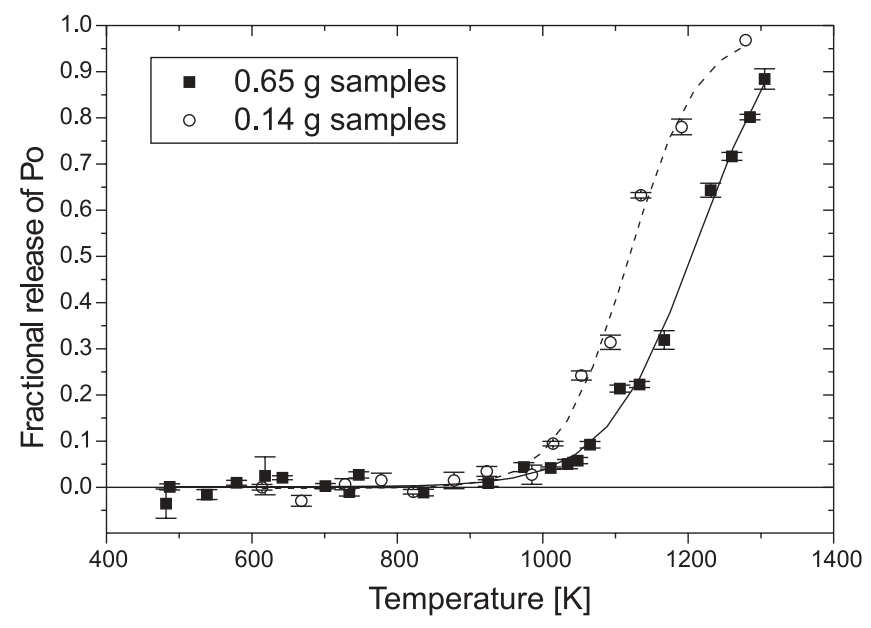

Fig. 4. Comparison of the release behaviour of polonium from LBE ( $1 \mathrm{~h}$ experiments) using different sample sizes in an $\mathrm{Ar} / 7 \%-\mathrm{H}_{2}$ atmosphere as a function of temperature.

the chalcogens are released at temperatures starting from $973 \mathrm{~K}$. The volatility increases in the order $\mathrm{Se}<\mathrm{Te}<\mathrm{Po}$. Accordingly, the temperatures at which $50 \%$ of the total amount of chalcogen is released decrease from $1300 \mathrm{~K}(\mathrm{Se})$ to $1270(\mathrm{Te})$ and $1200 \mathrm{~K}(\mathrm{Po})$. In the temperature range of interest for technical applications like liquid metal spallation targets (473-723 K) no release has been observed within the experimental errors indicated as error bars in the figures. Fig. 3 shows a comparison of the release behaviour of polonium in $\mathrm{Ar} / 7 \%-\mathrm{H}_{2}$ and water saturated $\mathrm{Ar}$ atmosphere. The presence of water does not lead to a pronounced increase of the volatility of polonium between 498 and $873 \mathrm{~K}$. The sample investigated at $1108 \mathrm{~K}$ suffered from oxidation in the water-containing atmosphere and had reacted with water and the quartz tissue within an hour to form presumably a $\mathrm{Pb} / \mathrm{Bi}$ silicate glass. However, these chemical reactions do not lead to a significant increase or decrease of the polonium evaporation rate.

Fig. 4 shows a comparison of the fractional release of polonium from LBE samples of different sizes as a function of temperature. For both sample sizes a measurable release of polonium occurs only at temperatures above 973 K. How- 
ever, above this temperature the release of polonium from $0.14 \mathrm{~g}$ samples is about twice as fast as from $0.65 \mathrm{~g}$ samples. From an evaluation of the surface to volume ratios and the radius ratios of the two sample sizes no clear conclusion can be drawn with respect to a desorption- or diffusioncontrolled process. However, a detailed evaluation of the mechanism of the release process is beyond the scope of this work.

The results of our long-term experiments are presented in Figs. 5 and 6. Fig. 5 shows the fractional release of polonium from LBE measured in an $\mathrm{Ar} / 7 \%-\mathrm{H}_{2}$ atmosphere at different temperatures as a function of time for periods up to 28 days. At 646 and $721 \mathrm{~K}$, which are temperatures considered for the operation of liquid metal spallation targets using LBE as the target material, no release is observed within the limits of the experimental errors. At $867 \mathrm{~K}$ polonium evaporates slowly with an evaporation rate of the order of $1 \%$ per day. Even at temperatures as high as $968 \mathrm{~K}$ it takes about 12 days to remove $85 \%$ of the present polonium. Therefore, a large concentration of polonium in the cover-gas system of a LBE spallation target due to evaporation processes seems

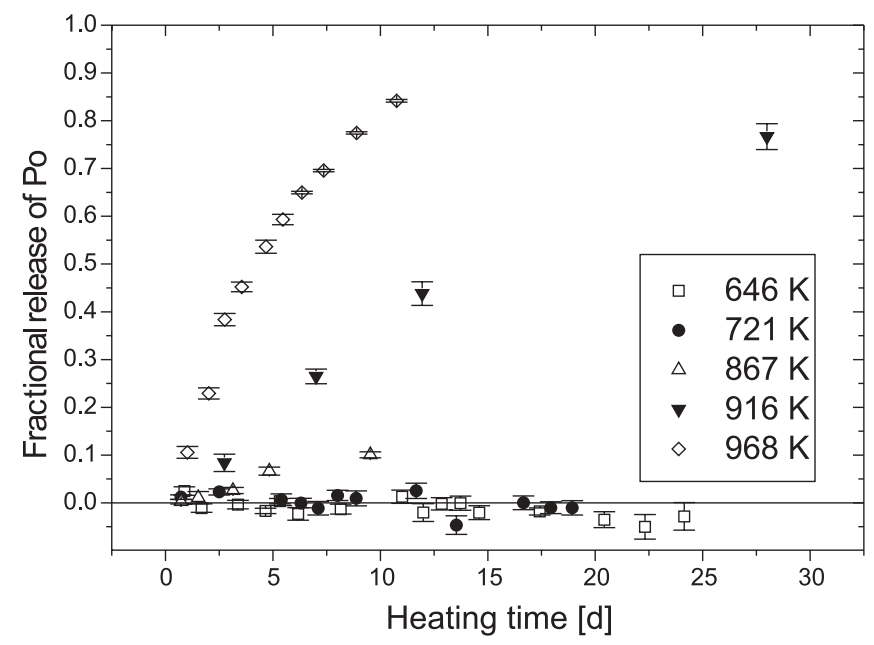

Fig. 5. Comparison of the long-term polonium release from LBE in an $\mathrm{Ar} / 7 \%-\mathrm{H}_{2}$ atmosphere at different temperatures as a function of heating time.

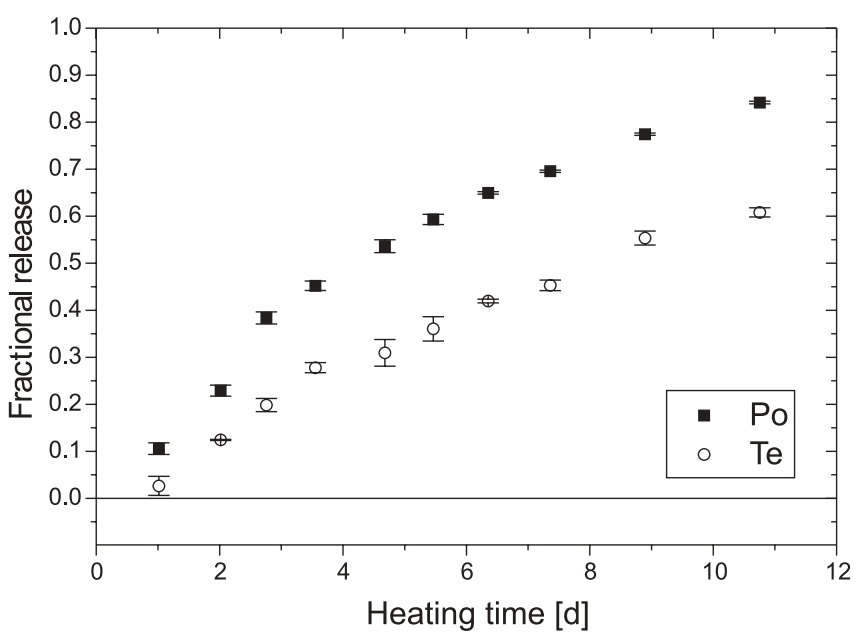

Fig. 6. Comparison of the long-term tellurium and polonium release from $\mathrm{LBE}$ in an $\mathrm{Ar} / 7 \%-\mathrm{H}_{2}$ atmosphere at $968 \mathrm{~K}$ as a function of heating time. unlikely. However, for such a system the release of polonium by other processes like sputtering or the formation of aerosols and dusts has to be taken into account as well.

A comparison of tellurium and polonium release from $\mathrm{LBE}$ in an $\mathrm{Ar} / 7 \%-\mathrm{H}_{2}$ atmosphere at $968 \mathrm{~K}$ is presented in Fig. 6. As already indicated by the results of short-term experiments the evaporation of Te from LBE is significantly slower than Po-evaporation.

In general, the results of long-term experiments show that the mechanism of the evaporation process does not change over long periods of time, i.e. no change of the reaction path is indicated. For the time dependency an approximate linear relation to the square root of release time is observed (Fig. 7) as generally known for release processes.

To assign or exclude possible reaction pathways we evaluated some thermochemical properties of the main species that might be involved in such an evaporation process. The main gas phase species considered are monoatomic chalcogens $\mathrm{Q}$, diatomic $\mathrm{Q}_{2}$ molecules, dioxides $\mathrm{QO}_{2}$, hydrides $\mathrm{H}_{2} \mathrm{Q}$, hydroxides $\mathrm{Q}(\mathrm{OH})_{2}$ and the gaseous diatomic molecules $\mathrm{PbQ}$ and $\mathrm{BiQ}(\mathrm{Q}=\mathrm{Se}, \mathrm{Te}, \mathrm{Po})$. From these species, the dioxides can be excluded because they will be reduced in the presence of hydrogen and metals such as lead. Equilibrium constants calculated from thermodynamic data [19] for reactions such as

$$
\mathrm{QO}_{2}+2 \mathrm{H}_{2} \leftrightarrows \mathrm{Q}+2 \mathrm{H}_{2} \mathrm{O}
$$

and

$$
\mathrm{QO}_{2}+2 \mathrm{~Pb} \leftrightarrows 2 \mathrm{PbO}+\mathrm{Q}
$$

indicate that the equilibrium is clearly dominated by the product side. This tendency is additionally increased by a stabilizing metal-chalcogen interaction ("coupled reduction") in solution [20].

Thermodynamic data for reactions of metal chalcogenides with hydrogen and water such as

$$
\mathrm{PbQ}+\mathrm{H}_{2} \leftrightarrows \mathrm{Pb}+\mathrm{H}_{2} \mathrm{Q}
$$

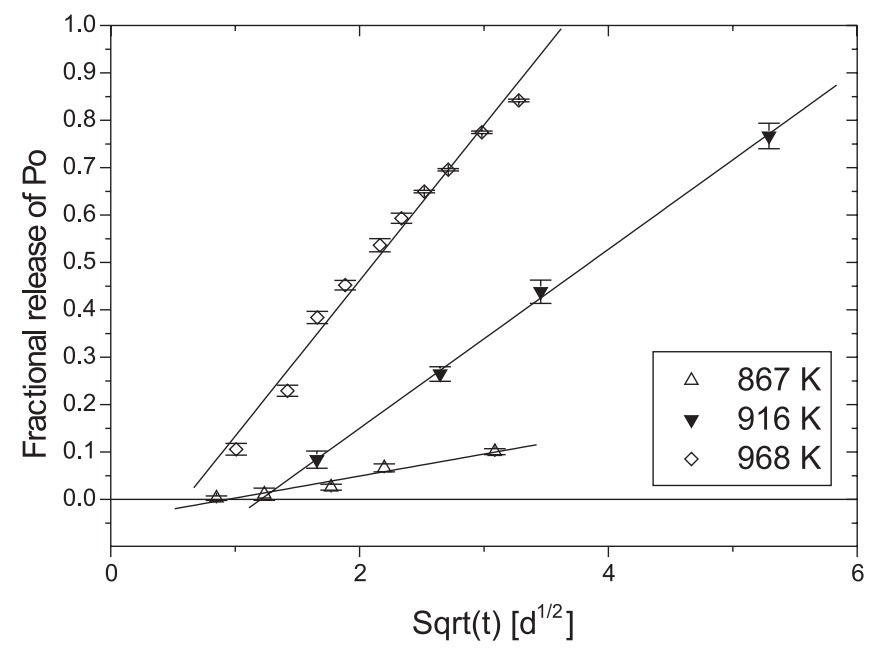

Fig. 7. Approximate linear relationship of polonium release at different temperatures and the square root of heating time. 
and

$$
\mathrm{PbQ}+\mathrm{H}_{2} \mathrm{O} \leftrightarrows \mathrm{PbO}+\mathrm{H}_{2} \mathrm{Q}
$$

show that the formation of chalcogen hydrides is not favoured. Experimental investigations indicate that polonium hydride is thermally unstable. It is possibly formed only under the presence of nascent hydrogen [4]. A more comprehensive discussion of the behaviour of hydrogen containing species in LBE will be given in a following paper.

Within this work we focus on monoatomic and diatomic chalcogens and diatomic lead and bismuth chalcogenides as gas phase species.

For the volatilisation process the following pathways have to be considered:

1) evaporation of the chalcogen $Q$ from LBE in form of single atoms according to

$$
\mathrm{Q}(\text { solv }) \rightarrow \mathrm{Q}(\mathrm{g}) \text {. }
$$

Approximate values for the accompanying enthalpy of evaporation can be calculated by subtracting the partial molar enthalpy of solution of the chalcogen in the liquid metal $\Delta \bar{H}_{\mathrm{Q} \text { in metal (I) }}^{\text {olv }}$ from the difference of the standard enthalpy of the gaseous monoatomic chalcogen $\Delta H \mathrm{Q}(\mathrm{g})$ and its enthalpy of melting $\Delta H_{\mathrm{m}} \mathrm{Q}$ :

$$
\Delta \bar{H}_{\mathrm{Q}}^{\mathrm{v}}=\left(\Delta H \mathrm{Q}(\mathrm{g})-\Delta H_{\mathrm{m}} \mathrm{Q}\right)-\Delta \bar{H}_{\mathrm{Q} \text { in metal (l) }}^{\text {solv }} .
$$

Temperature dependency has been neglected and the enthalpy of melting at the melting point has been used as an approximation for $\Delta H_{\mathrm{m}} \mathrm{Q}$.

2) evaporation as diatomic chalcogen molecules according to

$$
2 \mathrm{Q}(\text { solv }) \rightarrow \mathrm{Q}_{2}(\mathrm{~g}) .
$$

In analogy to monoatomic evaporation the enthalpy for this process can be expressed as the difference between standard enthalpy of the gaseous diatomic chalcogen minus twice the melting enthalpy of the chalcogen and the enthalpy associated with the solution of two atoms of $\mathrm{Q}$ in the liquid metal, hence:

$$
\Delta \bar{H}_{\mathrm{Q}_{2}}^{\mathrm{v}}=\left(\Delta H \mathrm{Q}_{2}(\mathrm{~g})-2 \Delta H_{\mathrm{m}} \mathrm{Q}\right)-2 \Delta \bar{H}_{\mathrm{Q} \text { in metal (I) }}^{\text {solv }} \text {. }
$$

3) evaporation in form of diatomic metal chalcogenides $M Q$ $(\mathrm{M}=\mathrm{Pb}, \mathrm{Bi} ; \mathrm{Q}=\mathrm{Se}, \mathrm{Te}, \mathrm{Po})$

$$
\mathrm{Q}(\text { solv })+\mathrm{M}(\mathrm{l}) \rightarrow \mathrm{MQ}(\mathrm{g}) \text {. }
$$

The associated enthalpy can be calculated from the enthalpy values of the monoatomic species $\mathrm{M}$ and $\mathrm{Q}$, their enthalpies of melting, the partial molar enthalpy of solution of the chalcogen $\mathrm{Q}$ in the liquid metal $\mathrm{M}$ and the dissociation enthalpy of the diatomic molecules MQ using the following equation:

$$
\begin{aligned}
\Delta \bar{H}_{\mathrm{MQ}}^{\mathrm{v}}= & \left(\Delta H \mathrm{Q}(\mathrm{g})-\Delta H_{\mathrm{m}} \mathrm{Q}\right)+\left(\Delta H \mathrm{M}(\mathrm{g})-\Delta H_{\mathrm{m}} \mathrm{M}\right) \\
& -\Delta \bar{H}_{\mathrm{Q} \text { in metal (I) }}^{\text {solv }}-\Delta H^{\text {diss }} \mathrm{MQ}(\mathrm{g}) .
\end{aligned}
$$

We have calculated enthalpies of evaporation for these processes using available thermochemical data for $\Delta H \mathrm{Q}(\mathrm{g})$, $\Delta H \mathrm{M}(\mathrm{g}), \Delta H_{\mathrm{m}} \mathrm{Q}, \Delta H_{\mathrm{m}} \mathrm{M}$ and $\Delta H \mathrm{Q}_{2}(\mathrm{~g})$ from [19] (Se, $\mathrm{Te}$ ) and [21] (Po). Values for $\Delta \bar{H}_{\mathrm{Q}}^{\text {sin metal (I) }}$ have been calculated using Miedema's macroscopic atom model [22]. Details of the parameterisation of the model and the calculation procedure can be found in [20]. The values for $\Delta \bar{H}_{\mathrm{Q}}^{\text {sil }}$ in metal (1) calculated in this way are very similar for the chalcogens in liquid $\mathrm{Pb}$ and $\mathrm{Bi}$, respectively. Furthermore, LBE does not deviate to far from ideal behaviour. Therefore, we give mean values for $\Delta \bar{H}_{\mathrm{Q} \text { in metal (I) }}^{\text {olv }}$ calculated for lead and bismuth below.

Values for the dissociation enthalpies of diatomic molecules $\Delta H^{\text {diss }} \mathrm{MQ}(\mathrm{g})$ are estimated using a method described in [23]. The values for dissociation enthalpies of homonuclear diatomic molecules $\mathrm{M}_{2}$ and $\mathrm{Q}_{2}$ required for these calculations have been taken from $[19,21]$.

The results of these calculations are compiled in Table 1. From these values it can be concluded that evaporation of chalcogens from LBE in the form of lead chalcogenide molecules seems to be the least probable reaction path from a thermochemical point of view. For a discussion on the remaining possibilities we discuss the release process as three possible series of successive reactions as shown in Fig. 8.

For each of these reaction sequences the rate of release and hence the observed sequence of release rates (experimentally: $\mathrm{Se}<\mathrm{Te}<\mathrm{Po}$ ) will be determined by the reaction step involving the highest energy of activation. Thus, if the release process is diffusion controlled the sequence of release rates will be determined by the sequence of activation energies of diffusion. Nevertheless, the actual species released could still be either of the three possibilities $\mathrm{Q}_{2} \mathrm{Q}_{2}$ or

\begin{tabular}{|c|c|c|c|c|c|}
\hline Chalcogen Q & $\begin{array}{c}\Delta \bar{H}_{\mathrm{Q} \text { in } \mathrm{Pb} / \mathrm{Bi}(\mathrm{l})}^{\mathrm{solv}} \\
{\left[\mathrm{kJ} \mathrm{mol}^{-1}\right]}\end{array}$ & $\begin{array}{c}\Delta \bar{H}_{\mathrm{Q}}^{\mathrm{v}} \\
{\left[\mathrm{kJ} \mathrm{mol}^{-1}\right]}\end{array}$ & $\begin{array}{c}\Delta \bar{H}_{\mathrm{Q}_{2}}^{\mathrm{v}} \\
{\left[\mathrm{kJ} \mathrm{mol}{ }^{-1}\right]}\end{array}$ & $\begin{array}{c}\Delta \bar{H}_{\mathrm{PbQ}}^{\mathrm{v}} \\
{\left[\mathrm{kJ} \mathrm{mol}^{-1}\right]}\end{array}$ & $\begin{array}{c}\Delta \bar{H}_{\mathrm{BiQ}}^{\mathrm{v}} \\
{\left[\mathrm{kJ} \mathrm{mol}^{-1}\right]}\end{array}$ \\
\hline $\mathrm{Se}$ & -38.7 & 268.2 & 203.8 & 219.4 & 177.9 \\
\hline $\mathrm{Te}$ & -11.2 & 205.4 & 147.8 & 218.0 & 164.5 \\
\hline Po & -8.8 & 185.4 & 159.3 & 231.3 & 176.3 \\
\hline
\end{tabular}
MQ. No literature data are available for diffusion of chalcogens in LBE. Therefore, we have to rely on estimations for evaluating the corresponding activation energies. The energy of activation for the process of self-diffusion in liquid lead is $18.6 \mathrm{~kJ} / \mathrm{mole}$ [24]. For diffusion of lead and bismuth in LBE activation energies of 9.6 and $7.7 \mathrm{~kJ} / \mathrm{mole}$, respectively, have been estimated from molecular dynam-

Table 1. Calculated values for mean partial molar enthalpies of solution of the chalcogens $\mathrm{Q}(\mathrm{Q}=\mathrm{Se}, \mathrm{Te}, \mathrm{Po})$ in liquid lead and bismuth $\left(\Delta \bar{H}_{\mathrm{Q} \text { in Pb/Bi }}^{\text {solv }}(1)\right)$ and mean partial molar enthalpies of evaporation from liquid lead and bismuth of the chalcogens $\mathrm{Q}$ in the monoatomic $\left(\Delta \bar{H}_{\mathrm{Q}}^{\mathrm{v}}\right)$ and diatomic state $\left(\Delta \bar{H}_{\mathrm{Q}_{2}}^{\mathrm{v}}\right)$ and as diatomic metal chalcogenides molecules $\left(\Delta \bar{H}_{\mathrm{PbQ}}^{\mathrm{v}}\right.$ and $\left.\Delta \bar{H}_{\mathrm{BiQ}}^{\mathrm{v}}\right)$. 


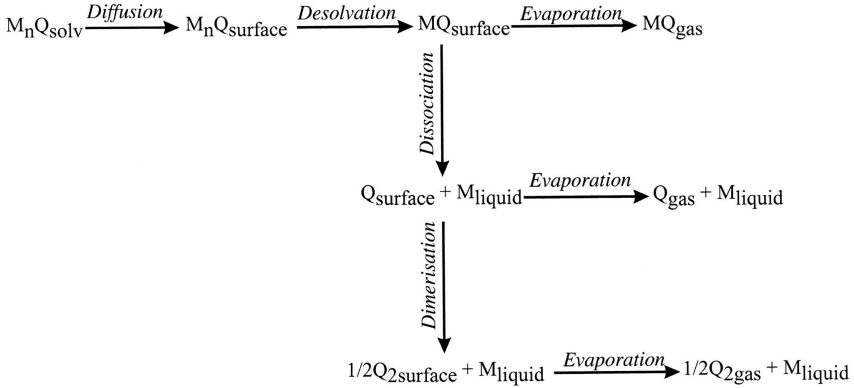

Fig. 8. Scheme of possible reaction steps involved in the release of chalcogens from LBE.

ics calculations [25]. Experimental values vary in the range from 11.6 to $40 \mathrm{~kJ} / \mathrm{mole}$ [26]. For diffusion of selenium in liquid tin an activation energy of $13.4 \mathrm{~kJ} /$ mole has been determined [26]. Assuming similar or even somewhat larger values for chalcogen diffusion in LBE it still seems unlikely that diffusion is the rate determining step since activation energies for the evaporation step are expected to be in the order of magnitude of the enthalpies of evaporation compiled in Table 1.

The enthalpy values for the evaporation of monoatomic chalcogens are in agreement with the experimentally observed sequence of evaporation rates. Assuming that the corresponding activation energy values are similar, this could be interpreted as a supporting fact for the release in the form of monoatomic chalcogens. However, if there is a high enough concentration of chalcogen in the liquid alloy to facilitate the formation of $\mathrm{Q}_{2}$ molecules, the evaporation in form of $\mathrm{Q}_{2}$ species should be favoured compared to the release as monoatomic chalcogens. This has to be mainly taken into account for selenium and tellurium. Chemical analysis of the LBE used in our experiments show that the concentration of these elements are below the detection limits $(<2 \mathrm{ppm}$, ICP-OES), but still these elements can be present as inactive impurities with much higher concentrations than those of the radioactive tracer determined by $\gamma$-ray spectroscopy. Polonium however is present in our samples in a carrier-free state. Therefore, the formation of $\mathrm{Po}_{2}$ is very unlikely. Considering the approximate character of our calculations the evaporation in form of BiQ molecules is possible as well. In particular, relatively small values for the enthalpies of evaporation of $\mathrm{BiQ}$ have been calculated for $\mathrm{Q}=\mathrm{Se}$ and $\mathrm{Po}$. Thus, no certain decision can be made based on the results of our calculations. Finally, it is also possible that the release process for selenium, tellurium and polonium is not identical. Definitely, the evaporation in form of BiQ molecules is much more likely than evaporation as $\mathrm{PbQ}$.

For further clarification of the reaction pathway, concentration dependent evaporation experiments should be performed to investigate $\mathrm{Q} / \mathrm{Q}_{2}$-problem. For selenium and tellurium this can be achieved by the addition of inactive chalcogen as a carrier, which also reflects the operating conditions of a LBE spallation target, i.e. higher concentrations of spallation products.

Furthermore, larger scale experiments in a flow system with varying gas phase composition and with the addition of suitable representatives for spallation products would be useful to establish a deeper understanding of the processes occurring in such a target. The interaction of polonium with other spallation products such as electropositive metals will most likely lead to a decrease of its evaporation rate [20].

Finally, a study of segregation effects of polonium in solid LBE is of interest with respect to the storage of a spallation target after decommissioning. Given the fact that LBE melts at $398 \mathrm{~K}$ relatively high diffusion rates can be expected within the target material after freezing and decommissioning. Results of calculations of approximate partial molar enthalpies of segregation of polonium in lead and bismuth [20] indicate that a segregation of chalcogens in solid lead and bismuth is not highly probable, but cannot be ruled out as well. Indeed, in our evaporation experiments we have observed small segregation effects for the selenium samples that manifested themselves in the count rates of the lowest energy $\gamma$-lines (as a consequence, these lines were excluded from release evaluations).

Acknowledgment. This work has been supported by the BBW under Contract Nr. 01.0298 "Megapie-Test", EU Contract No. FIKW-CT2001-00159 and the EU-RTD project TARGISOL (HPRI-CT-200150033). Furthermore, we thank Dr. R. Dressler for assistance in $\gamma$-ray spectroscopy, Mr. H.-U. Aebersold for neutron activation of LBE samples and Mr. D. Piguet for preparing the LBE samples for heavy ion implantation.

\section{References}

1. Salvatores, M., Bauer, G. S., Heusener, G.: The MEGAPIE Initiative. PSI-Report Nr. 00-05, Paul Scherrer Institut, Villigen, Switzerland (2000).

2. Gromov, B. F., Belomitlev, Yu. S., Efimov, E. I., Leonchuk, M. P., Martinov, P. N. Orlov, Yu. I., Pankratov, D. V., Pashkin, Yu. G., Toshinsky, G. I., Chenukov, V. V., Shmatko, B. A., Stepankov, V. S.: Use of lead-bismuth coolant in nuclear reactors and acceleratordriven systems. Nucl. Engin. Design 173, 207 (1997).

3. Atchison, F.: Nuclide Production in the SINQ Target. Report SINQ/816/AFN-702, Paul Scherrer Institut, Villigen, Switzerland (1997).

4. Gmelin's Handbook of Inorganic and Organometallic Chemistry. $8^{\text {th }}$ edn., Polonium, Supplement Vol. 1, Springer-Verlag, Berlin (1990) p. 421.

5. Jennings, A. S., Proctor, J. F., Fernandez, L. P.: The Large Scale Separation of Polonium-210 from Bismuth. Du Pont Rep., Large Scale Production and Applications of Radioisoptes, DP-1066, 3, Du Pont de Nemour and Co, Aiken, SC, Savannah River Lab. Vacuum 17, 584 (1967).

6. Tupper, R. B., Minushkin, B., Peters, F. E., Kardos, Z. L.: Polonium Hazards Associated with Lead Bismuth Used as a Reactor Coolant. Proc. of the Intern. Conf. on Fast Reactors and Related Fuel Cycles, October 28-November 1 (1991), Kyoto, Japan, Vol. 4, pp. 5.6-1.

7. Pankratov, D. V., Yefimov, E. I., Burgreev, M. I.: Polonium Problem in Lead-Bismuth Flow Target. Proc. of the Intern. Workshop on the Technology and Thermal Hydraulics of Heavy Liquid Metals, March 25-28 (1996), Schruns, Austria, p. 9.23.

8. Furrer, M., Steinemann, M., Leupi, P.: Dampfdruck von Polonium210 über einer eutektischen Blei-/Wismut-Schmelze bei $350{ }^{\circ} \mathrm{C}$. TM-43-91-08, Paul Scherrer Institut, Villigen, Switzerland (1991).

9. Buongiorno, J., Larson, C., Czerwinski, K. R.: Speciation of polonium released from molten lead bismuth. Radiochim. Acta 91, 153 (2003).

10. Yefimov, E. I., Pankratov, D. V.: Polonium and volatile radionuclides output from liquid metal target into ion guide and gas system. Proc. of the 2. Intern. Conf. on Accelerator-Driven Transmutation Technologies and Applications, June 3-7 (1996), Kalmar, Sweden, p. 1121.

11. Levanov, V. I., Pankratov, D. V., Yefimov, E. I.: The Estimation of Radiation Danger of Gaseous and Volatile Radionuclides in Accelerator Driven System with $\mathrm{Pb}-\mathrm{Bi}$ Coolant. Proc. of the 3 . 
Intern. Conf. on Accelerator-Driven Transmutation Technologies and Applications, June 7-11 (1999), Prague, Czech Republic, http://www.fjfi.cvut.cz/con_adtt99/.

12. Fischer, W. E.: Dampfdruck und Aktivierung flüchtiger Spallationsprodukte aus dem SINQ-Target. Report SINQ/821/FIN-716, Schweizerisches Institut für Nuklearforschung, Villigen, Switzerland (1987).

13. Li, N., Yefimov, E., Pankratov, D.: Polonium Release from an ATW Burner System with Liquid Lead-Bismuth Coolant. Report LA-UR-98-1995, Los Alamos National Laboratory, USA (1998).

14. Köster, U., for the ISOLDE Collaboration: ISOLDE target and ion source chemistry. Radiochim. Acta 89, 749 (2001).

15. Audi, G., Bersillon, O., Blachot, J. Wapstra, A. H.: The NUBASE evaluation of nuclear and decay properties. Nucl. Phys. A 729, 3 (2003).

16. Köster, U., Bergmann, U. C., Carminati, D., Catherall, R., Cederkäll, J., Correia, J. G., Crepieux, B., Dietrich, M., Elder, K., Fedoseyev, V. N., Fraile, L., Franchoo, S., Fynbo, H., Georg, U., Giles, T., Joinet, A., Jonsson, O. C., Kirchner, R., Lau, Ch., Lettry, J., Maier, H. J., Mishin, V. I., Oinonen, M., Peräjärvi, K., Ravn, H. L., Rinaldi, T., Santana-Leitner, M., Wahl, U., Weissman, L.: Oxide fiber targets at ISOLDE. Nucl. Instrum. Methods B 204, 303 (2003).

17. http://nucleardata.nuclear.lu.se/nucleardata/toi/.
18. http://physics.nist.gov/PhysRefData/XrayMassCoef/tab3.html.

19. Barin, I.: Thermochemical Data of Pure Substances. VCH, Weinheim (1995).

20. Neuhausen, J., Eichler, B.: Extension of Miedema's Macroscopic Atom Model to the Elements of Group 16 (O, S, Se, Te, Po). PSI-Report 03-13, Paul Scherrer Institute, Villigen, Switzerland, September (2003).

21. Eichler, B.: Die Flüchtigkeitseigenschaften des Poloniums. PSIReport 02-12, Paul Scherrer Institute, Villigen, Switzerland, June (2002).

22. de Boer, F. R., Boom, R., Mattens, W. C. M., Miedema, A. R., Niessen, A. K.: Cohesion in Metals, Transition Metal Alloys. North-Holland, Amsterdam (1988).

23. Miedema, A. R., Gingerich, K. A.: On the enthalpy of formation of diatomic intermetallic molecules. J. Phys. B: Atom. Molec. Phys. Vol. 12, 2255 (1979).

24. Leymonie, C.: Radioactive Tracers in Physical Metallurgy. Chapman and Hall, London (1963) p. 112.

25. Celino, M. Conversano, R., Rosato, V.: Atomistic simulation of liquid lead and lead-bismuth eutectic. J. Nucl. Materials 301, 64 (2002).

26. Landolt-Börnstein Zahlenwerte und Funktionen aus Physik, Chemie, Astronomie, Geophysik und Technik. 6. Auflage, II. Band, 5. Teil B, Springer, Berlin (1968). 